\title{
Acute Calculus Cholecystitis Misdiagnosed As Ileocecal Tumor in an Elderly Male: Review of the Ultrasonographic Findings: A Case Report
}

\author{
Sule $\mathrm{MB}^{1^{*}}$, Shamaki AMB ${ }^{1}$, Umar $\mathrm{AU}^{2}$, Gele $\mathbf{I H}^{1}$, Ribah $\mathrm{MM}^{3}$ and Aliyu $\mathrm{AZ}^{3}$ \\ ${ }^{1}$ Radiology Department, Usmanu Danfodiyo University, Sokoto. \\ ${ }^{2}$ Radiology Department, Gombe State University, Gombe. \\ ${ }^{3}$ Radiology Department, Usmanu Danfodiyo University Teaching Hospital Sokoto.
}

*Corresponding Author: Sule MB, Radiology Department, Usmanu Danfodiyo University, Sokoto.

Received date: December 19, 2021; Accepted date: January 03, 2021; Published date: January 14, 2022

Citation: Sule MB, Shamaki AMB, Umar AU, Gele IH, Ribah MM, et al. (2022). Acute Calculus Cholecystitis Misdiagnosed As Ileocecal Tumor in an Elderly Male: Review of the Ultrasonographic Findings: A Case Report. J Clinical Research and Reports, 10(3); DOI:10.31579/2690-1919/223

Copyright: (C) 2022, Sule MB. This is an open access article distributed under the Creative Commons Attribution License, which permits unrestricted use, distribution, and reproduction in any medium, provided the original work is properly cited.

\begin{abstract}
Gallstones present as acute calculus cholecystitis in about $20 \%$ of individuals with symptomatic disease, having a wide range of symptom severity. The adult population is most often affected in about 10-15\% within the developed countries. This is a 75-year-old man that was referred for a confirmatory ultrasonography from a peripheral health centre on account of an entertained ileocecal tumor following an abdominal ultrasound scan done in a local health care facility. The patient had an abdominal ultrasonography that showed an impacted calculus in the infundibulum of the gallbladder measuring about $30 \mathrm{~mm} \times 30 \mathrm{~mm}$ in dimension with associated distended gall bladder; this shows thick and trabeculated wall, heterogenous content with circumferential hypoechoic halo of acute cholecystitis. The patient had percutaneous cholecystectomy in the peripheral care facility and was reported to have done considerably well for discharge. We report the ultrasonographic findings of acute calculus cholecystitis due to its peculiarity and presentations.
\end{abstract}

Keywords: gallstone; hypoechoic halo; sludge; tenderness; ultrasonographic findings; ACC; cholecystitis

\section{Introduction}

Acute calculus cholecystitis (ACC) follows an inflammatory or infectious process affecting the gall bladder wall most often accompanying an impacted gall bladder calculus in the infundibulum or in the cystic duct $[1,2]$. Cholecystitis however may occur without the presence of gall stones and is termed acalculous cholecystitis [3].

Acute cholecystitis is the most common complication of cholelithiasis, this represents about a third of all surgical emergencies with hospital admissions, though most of the aspects of the disease remains debatable [1].

Acute calculus cholecystitis occurs following gallbladder contraction against a cystic duct that has been obstructed by calculus, leading to inflammation with subsequent ischemia of the gallbladder wall [4].

Gallbladder infection is most commonly acute cholecystitis, this is often triggered by three basic mechanisms, these are obstruction of the cystic duct by gallstones, release of lysolecithin, and ascending bacterial infection of the biliary fluid [5].
Acute calculous cholecystitis has some complications, impaired liver function happens to be the most common, delayed or improper care may often lead to an aggravated liver damage, liver failure and subsequent death [6].

Cholelithiasis in the developed countries has a prevalence of about 10$15 \%$ among the adult population, with associated independent contributory factors which include family history, genetic predisposition, ethnic background, female gender and the patients age [7-9].

The diagnosis of gallstones is mainly following imaging, conventional radiography of the abdomen detects gallstones in about $10-15 \%$ of cases, ultrasonography and computed tomography (CT) are often preferred, with ultrasonography been more useful than $\mathrm{CT}$ in the initial evaluation of acute biliary disease because ultrasound helps to triage patients who require further imaging than those that may not require [10-12]. Acute gall bladder disease may also be imaged by magnetic resonance imaging, cholescintigraphy and endoscopic retrograde cholangiopancreatography (ERCP) [10]. 
Acute calculus cholecystitis may be treated medically and mainly by surgical approach, depending on the state of the patient, medical treatment basically comprises of rehydration and antimicrobial therapy, while surgical extraction of the calculus may either be laparoscopic or following percutaneous cholecystectomy depending on the skills and available facilities [1-11].

Cholecystitis and biliary colic may also encounter some complications, these may include empyema, sepsis, gangrene, pancreatitis, perforation and peritonitis to mention but a few $[1,12,13]$.

\section{Case Report}

This is a 75-year-old farmer that was referred for a confirmatory ultrasonography of the abdomen following an initial scan from a local health care facility that proffered a diagnosis of an ileocecal tumor.

The patient at the time of result is an elderly man, not pale, not dehydrated, not confused and oriented, not in any form of distress but had jaundice in both eyes. The patient had a stable blood pressure of $130 / 75 \mathrm{mmHg}$, normal pulse rate of 80 beats/minute and a respiratory rate of about 14 cyles per minute. The patient had no finger clubbing demonstrated.

The patient had a normal PCV of about $34 \%$ but showed elevated white blood count of 15,000 per microliter of blood and has a normal erythrocyte sedimentation rate of about $17 \mathrm{~mm} / \mathrm{hr}$. The patient had normal liver function test with no obvious derangement.

The abdominal and pelvic sonography showed an impacted oval echogenicity with posterior acoustic shadowing located within the infundibulum and measuring about $30 \mathrm{~mm} \times 30 \mathrm{~mm}$ in mediolateral and craniocaudal diameters (Figures; $1,3 \& 4$ ). The gallbladder shows marked distention $(130 \mathrm{~mm} \times 60 \mathrm{~mm}$ in craniocaudal and mediolateral diameter respectively; figures $2 \& 4$ ) with heterogeneous sludge, circumferential wall thickening $(17 \mathrm{~mm}$; figure 2$)$ with trabeculation and intraluminal outpouches and also surrounding hypoechoic halo of acute cholecystitis; figure 4 . There is associated mild hepatomegaly but the remaining biliary ducts show normal appearances. The remaining abdominal and pelvic organs appeared within normal limit for the patient's age. A diagnosis of acute calculus cholecystitis was concluded at.

No associated complication of pancreatitis, peri-gallbladder fluid to suspect leakage or obvious hepatic parenchymal changes were demonstrated following the abdominal ultrasonography.

The patient was given the result of these findings to his referring physician from a peripheral hospital, it was gathered from a relation that he had a successful percutaneous cholecystectomy and was discharged home thereafter.

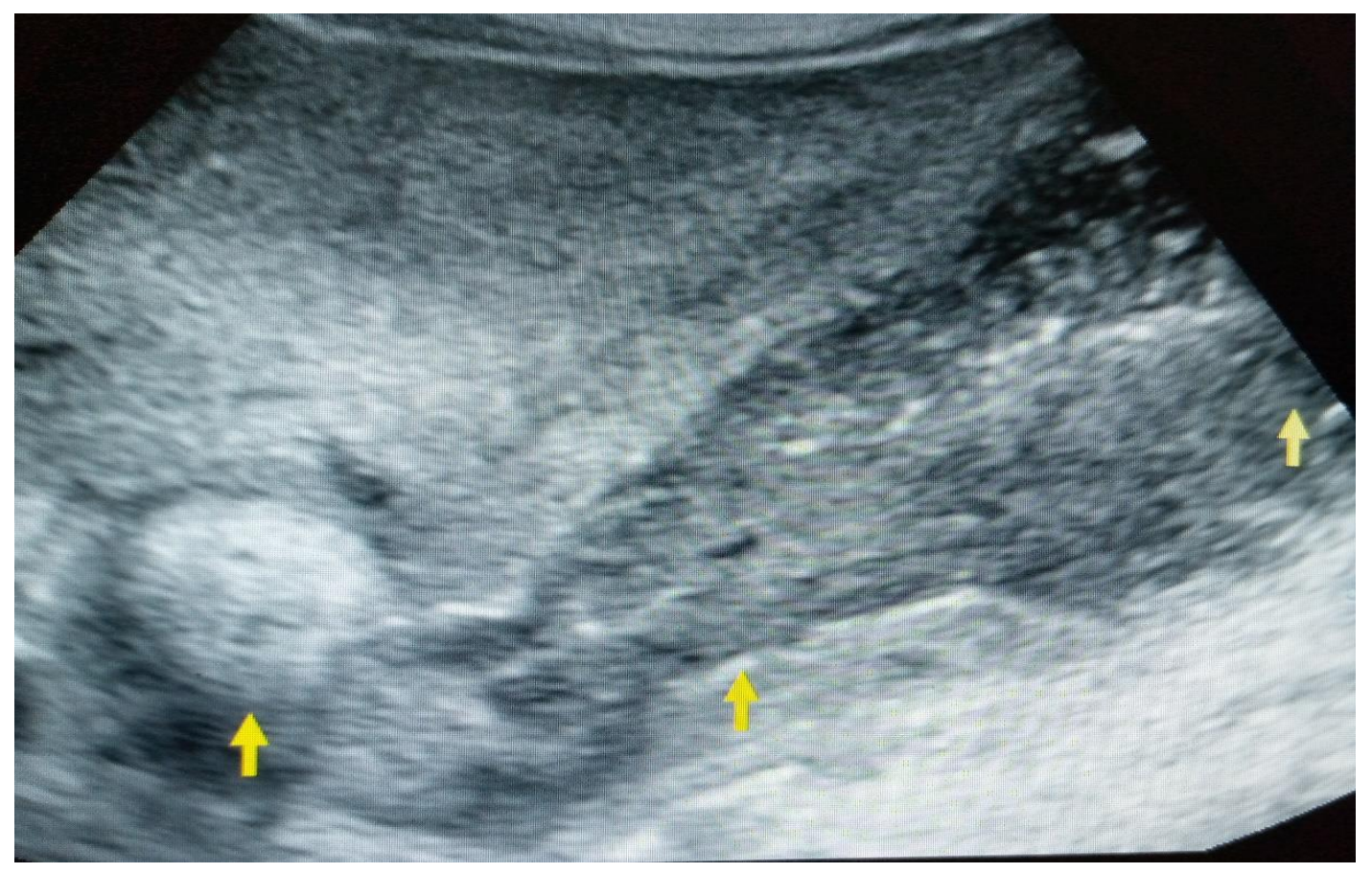

Figure 1: Abdominal ultrasonogram showing an oval echogenic area; calculus in the infundibulum of the gallbladder with surrounding acoustic shadow (left arrow), this measures about $30 \mathrm{~mm} \times 30 \mathrm{~mm}$ in size. The middle arrow shows thick wall while the right show sludge within the gallbladder lumen. 


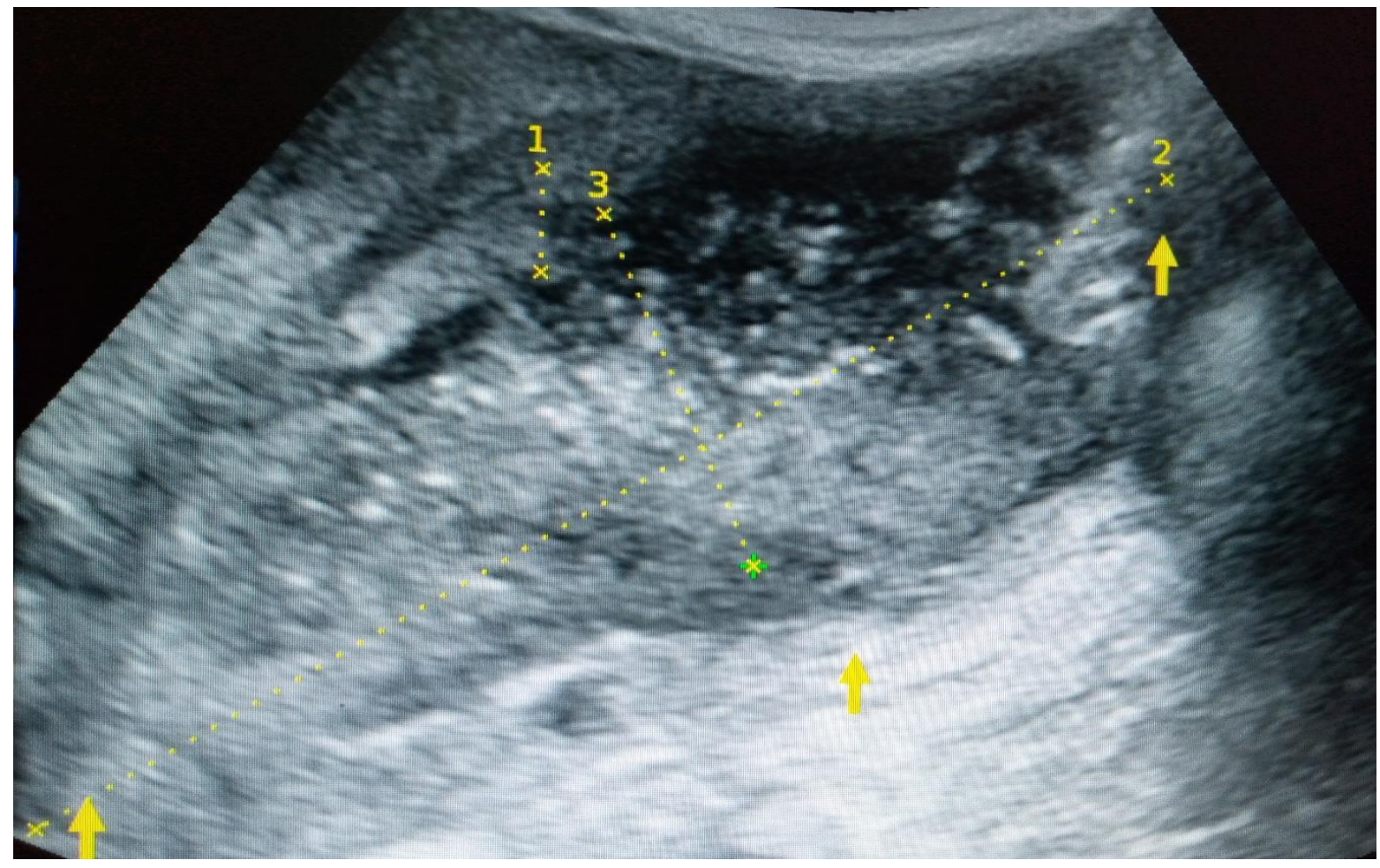

Figure 2: Abdominal ultrasonogram showing distended gall bladder with surrounding peripheral hypoechoic halo of acute cholecystitis; the gallbladder measures about $130 \mathrm{~mm} \times 60 \mathrm{~mm}$ in length and width. Wall thickness is about $17 \mathrm{~mm}$.

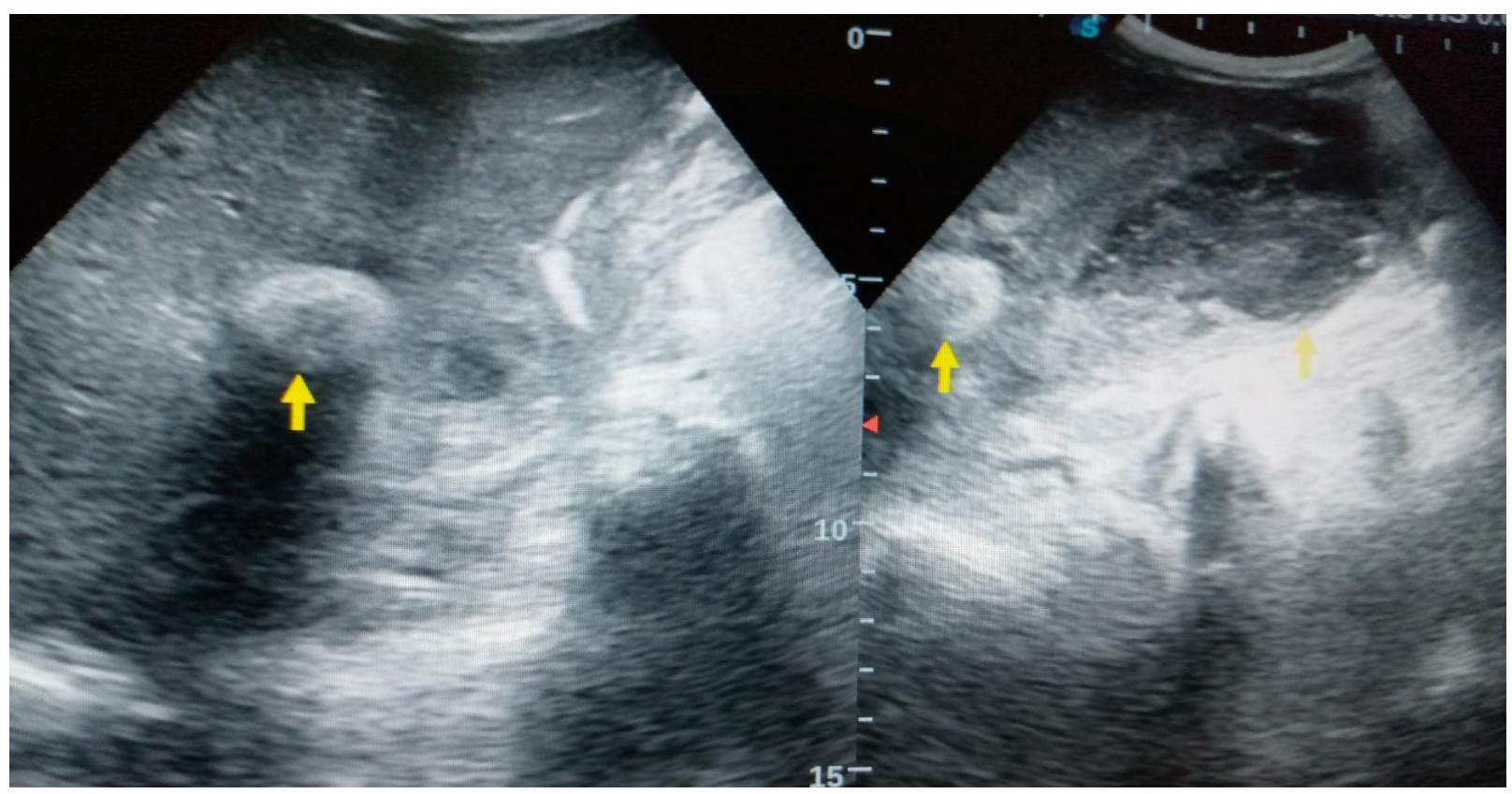

Figure 3: Abdominal ultrasonogram showing the enlarged liver, the impacted calculus with marked posterior acoustic shadow all on the left image and a thick-walled distended bladder with same calculus on the left image. 


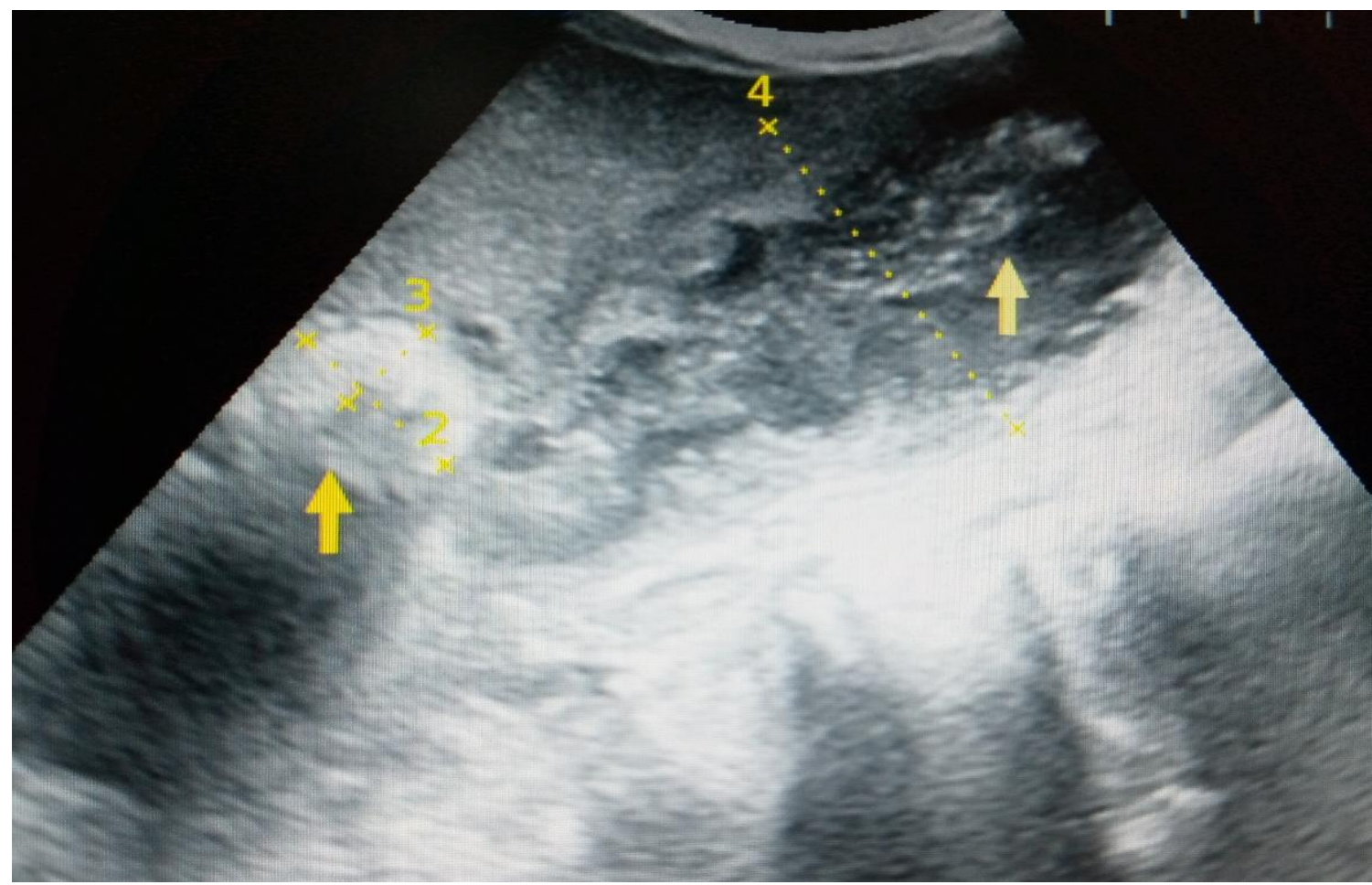

Figure 4: Abdominal ultrasonogram showing the thick and trabeculated wall of the gallbladder with intraluminal nodularity or hump-like appearance, heterogeneous sludge (right arrow), peripheral and circumferential hypoechoic halo of acute cholecystitis and the impacted calculus with posterior acoustic shadow (left arrow).

\section{Discussion}

Acute calculus cholecystitis (ACC) follows an inflammatory or infectious process affecting the gall bladder wall most often accompanying an impacted gall bladder calculus in the infundibulum or in the cystic duct $[1,2]$, the index case had an impacted calculus in the cystic duct with associated features of acute inflammatory process thereby conforming to these literatures.

Gallstone disease is often seen among the elderly population and predominant with the female gender as documented in most literatures, the index case happens to be elderly but however of the male gender.

Cholelithiasis may be associated with independent contributory factors which include family history, genetic predisposition, ethnic background, female gender and the patients age [6-8], the index case however has no family history of similar occurrence, not a female but of the elderly population.

Gall bladder infection is most commonly acute cholecystitis, this is often triggered by three basic mechanisms, though initially with obstruction of the cystic duct by gallstones, release of lysolecithin, and ascending bacterial infection of the biliary fluid [5], the index case might also not be an exception to these since the initial trigger is often obstruction of the cystic duct by a gallstone which was also demonstrated in this case thereby conforming to this literature.

Acute calculus cholecystitis is best imaged following ultrasonography, CT and conventional abdominal radiography with ultrasonography been preferred over most imaging, the index case was also diagnosed following an abdominal ultrasonography, thereby conforming to most literatures.

The ultrasonographic features reported in most literatures are often that of an impacted calculus in the gall bladder infundibulum or cystic duct, with a distended thick-walled gall bladder having heterogeneous sludge content with circumferential hypoechoic halo; the index case also had similar findings, thereby conforming to that documented in the literature.

The management approach of ACC is mainly by medical and surgical approach, the index case had a course of antibiotics and subsequently had a percutaneous cholecystectomy conforming to that reported in most literatures.

Cholecystitis and biliary colic may also encounter some complications, these may include empyema, sepsis, gangrene, pancreatitis, perforation and peritonitis to mention but a few $[1,12,13]$, the patient under review has no documented or observed complications as at the time of this report.

\section{Conclusion}

Acute calculus cholecystitis can be diagnosed following basic abdominal ultrasonography, this should be performed immediately in patients with high index of suspicion to alleviate morbidity and reduce complications.

\section{References}

1. Gomes CA, Junior CS, Di Saveiro S, Sartelli M, Kelly MD, Gomes CC, et al. (2017). Acute calculous cholecystitis: Review of current best practices. World J Gastrointest Surg. 2017; 9:118 126.

2. Shaffer EA. (2006). Gallstone disease: Epidemiology of gallbladder stone disease. Best Pract Res Clin Gastroenterol. 2006; 20:981-996.

3. Bridges F, Gibbs J, Melamed J, Cussatti E, White S. (2018). Clinically diagnosed cholecystitis: a case series. J Surg Case Rep. 2018; 2:1-2.

4. Gross AR, Bacaj PJ, Williams HJ. (2020). Educational Case: Gallstones, Cholelithiasis, and Cholecystitis. Academic Radiology. 2020; 7:1-5. 
5. Lammert F, Sauerbruch T: Gallensteine. Gastroenterologe. 2007; 26:461-476.

6. Tian Y, Suo X. (2020). Surgical treatment of acute calculous cholecystitis complicated with hepatic dysfunction. Medicine. 2020; 99:24(e20239).

7. Schuld J, Glanemann M. (2015). Acute Cholecystitis. Gastrointest Med Surg. 2015; 31:163-165.

8. Stinton LM, Shaffer EA. (2012). Epidemiology of gallbladder disease: cholelithiasis and cancer. Gut Liver. 2012; 6:172-187.

9. Stinton LM, Myers RP, Shaffer EA. (2010). Epidemiology of gallstones. Gastroenterol Clin North Am. 2010; 39:157-169.
10. O’Connor OJ, Maher MM. (2011). Imaging of Cholecystitis. Am J Roent. 2011; 196: W367-W374.

11. Harvey RT, Miller WT Jr. (1999). Acute biliary disease: initial CT and follow-up US versus initial US and follow-up CT. Radiology. 1999; 213:831-836.

12. Ansaloni L, Pisano M, Coccolini F, Peitzmann AB, Fingerhut A, Catena F, et al. (2016). WSES guidelines on acute calculous cholecystitis. World J Emerg Surg. 2016; 11:25.

13. Ternberg JL, Keating JP. (1975). Acute Acalculous Cholecystitis: Complications of Other Illnesses in Childhood. Arch Surg. 1975; 110:543-547.
This work is licensed under Creative Commons Attribution 4.0 License

To Submit Your Article Click Here: $\quad$ Submit Manuscript
Ready to submit your research? Choose Auctores and benefit from:

$>$ fast, convenient online submission

$>$ rigorous peer review by experienced research in your field

$>$ rapid publication on acceptance

$>$ authors retain copyrights

$>$ unique DOI for all articles

$>$ immediate, unrestricted online access

At Auctores, research is always in progress.

Learn more https://auctoresonline.org/journals/journal-of-clinical-research-andreports 